\title{
Erratum to: Cognitive profiles of poor readers of Kannada
}

\author{
Sonali Nag • Margaret J. Snowling
}

\section{Erratum to: Read Writ \\ DOI 10.1007/s11145-010-9258-7}

In the article 'Cognitive profiles of poor readers of Kannada' by Nag, S. and Snowling M. J. (Reading and Writing: The Inter-disciplinary Journal, 10.1007/ s11145-010-9258-7) the venn labels and values 'All five domains 13.8\%' and ' $37.9 \%$ ' in Fig. 1 should be switched around. We regret the error.

The online version of the original article can be found under doi:10.1007/s11145-010-9258-7.

S. Nag $(\bowtie) \cdot$ M. J. Snowling University of York, York, UK

e-mail: s.nag@psych.york.ac.uk

S. Nag

The Promise Foundation, Bangalore, India 


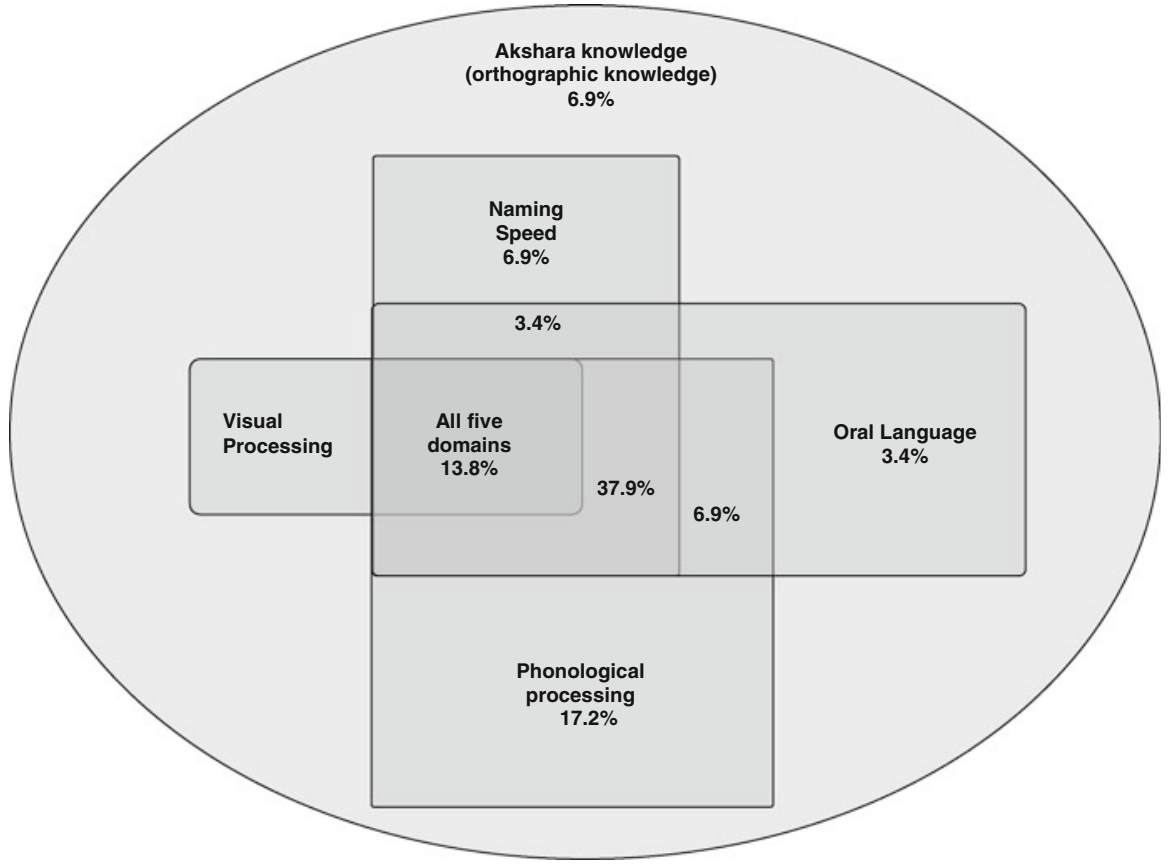

Fig. 1 Percentage of poor readers according to domains of difficulty 